\title{
Exploring gasoline oxidation chemistry in jet stirred reactors
}

\author{
Bingjie Chen ${ }^{\mathrm{a},{ }^{*}}$,Zhandong Wang ${ }^{\mathrm{a}}$, Jui-Yang Wang ${ }^{\mathrm{a}}$, Haoyi Wang ${ }^{\mathrm{a}}$, Casimir Togbéb, Pablo \\ Emmanuel Álvarez Alonso, ${ }^{\mathrm{a}, \mathrm{c}}$, Maram Almalki ${ }^{\mathrm{a}}$, Marco Mehld ${ }^{\mathrm{d}}$, W.J. Pitz ${ }^{\mathrm{d}}$, Scott Wagnon ${ }^{\mathrm{d}}$, \\ Kuiwen Zhang ${ }^{\mathrm{d}}$, Goutham Kukkadapu ${ }^{\mathrm{d}}$, Philippe Dagaut ${ }^{\mathrm{b}}$, S. Mani Sarathy,"* \\ a King Abdullah University of Science and Technology (KAUST), Clean Combustion Research Center (CCRC), \\ Thuwal, Saudi Arabia, 23955-6900 \\ b Centre National de la Recherche Scientifique INSIS, ICARE, IC, Avenue de la Recherche Scientifique, Orléans, \\ France \\ c Universidad de las Américas Puebla, San Andrés Cholula, Puebla, México \\ d Lawrence Livermore National Laboratory, Livermore, CA, United States \\ * Corresponding author email: bingjie.chen@kaust.edu.sa, mani.sarathy@kaust.edu.sa
}

\section{Abstract}

Recent decades have seen increasingly restrictive regulations applied to gasoline engines. Gasoline combustion chemistry must be investigated to achieve a better understanding and control of internal combustion engine efficiency and emissions. In this work, several gasoline fuels, namely the FACE (Fuel for Advanced Combustion Engines) gasolines, were selected as targets for oxidation study in jet-stirred reactors (JSR). The study is facilitated by formulating various gasoline surrogate mixtures with known hydrocarbon compositions to represent the real gasolines. Surrogates included binary mixtures of $n$-heptane and $i s o$-octane, as well as more complex multicomponent mixtures. The oxidation characteristics of FACE gasolines and their surrogates were experimentally examined in JSR-1 and numerically simulated under the following conditions: pressure 1 bar, temperature $500-1050 \mathrm{~K}$, residence time 1.0 and $2.0 \mathrm{~s}$, and two equivalence ratios ( $\phi=0.5$ and 1.0). In the high temperature region, all real fuels and surrogates showed similar 
oxidation behavior, but in the low temperature region, a fuel's octane number and composition had a significant effect on its JSR oxidation characteristics. Low octane number fuels displayed more low temperature reactivity, while fuels with similar octane number but a larger number of $\mathrm{n}$ alkane components were more reactive. A gasoline surrogate kinetic model was examined with FACE gasoline experiments either measured in JSR-2, or taken from previous work under the following conditions: pressure 10 bar, temperature $530-1200 \mathrm{~K}$, residence time $0.7 \mathrm{~s}$, and three equivalence ratios ( $\phi=0.5,1.0$ and 2.0). Comparison between FACE gasoline experimental results with surrogate model predictions showed good agreement, demonstrating considerable potential for surrogate fuel kinetic modeling in engine simulations.

Keywords: gasoline surrogate, jet stirred reactor, kinetic model, FACE gasoline fuel, oxidation chemistry. 


\section{Introduction}

Gasoline combustion engines are essential to civilization[1]; $20 \%$ of the world's total energy use is utilized for transportation[2]. $95 \%$ of the transportation energy source is from refined petroleum, while $40 \%$ of transportation energy is used for light-duty passenger cars, driven by spark ignition internal combustion engines[3]. Whereas vehicle electrification is of growing importance, vehicles powered by high-efficiency and low-emission gasoline engines coupled with electric motors will remain important in the future $[4,5]$.

In powering passenger cars, gasoline engines generate pollutants, e.g. $\mathrm{NO}_{\mathrm{x}}, \mathrm{CO}$, soot and unburnt hydrocarbons[6]. Restrictive regulations on engine exhausts have been made and applied in recent decades[7]. Several strategies, such as alternative bio-fuels[8], improving gasoline refining[9] and advanced engine design[10] have been made in an effort to reduce emissions and improve energy efficiency. Designing gasoline fuels which perform well across all engine running conditions is a promising path to controlling emissions and achieving higher energy efficiency[11]. To realize this goal, and to develop numerical models for fuel/engine design, it is essential to understand gasoline oxidation chemistry.

Real gasoline fuels have thousands of hydrocarbon components, making numerical simulations problematic; consisting of several hydrocarbon molecules, surrogates are used to represent real fuels as a viable approach[1, 12]. Proposed surrogates must have key physical and chemical properties similar to real fuels, e.g. H/C (hydrogen to carbon) ratio, density, average molecular weight, RON (research octane number) and MON (motor octane number)[1]. In addition, good surrogates should also predict gas-phase combustion properties, such as ignition 
delay time[13-15], laminar flame speed[16], species distributions in flames[17, 18] and jet-stirred reactor (JSR) oxidations[19, 20].

Considerable work has been done on studying oxidation of gasoline surrogates and real gasoline fuels[1]. Ignition delay times have been measured for binary primary reference fuels (PRF) [21-26], ternary primary reference fuels (TPRF) [31, 32], and multi-component surrogates [34-36], while flame speeds have been measured for PRFs [27-30] and TPRFs [33]. Recently, FACE (Fuels for Advanced Combustion Engines) gasolines have attracted scientific attention[1]. FACE gasolines were designed based on statistical methods and target values established by the Coordinating Research Council Advanced Vehicle, Fuel and Lubricant Committee Working Group[37]. Investigations on FACE gasolines have been performed on two alkane-rich, medium octane number, low sensitivity FACE fuels, FACE A and C, with measurements of ignition delay time[15, 38], species profiles in premixed flames[17] and JSR oxidation[20]; two high octane number, high sensitivity FACE fuels, FACE F and G, with measurements of ignition delay time [14] and JSR oxidation[19]; and two low octane number, low sensitivity FACE fuels, FACE I and J, with measurements of ignition delay time[39]. All six FACE fuels--regardless of their different octane number and hydrocarbon compositions--exhibited similar reactivity in the high temperature region[39]. In the low temperature region, however, different gasolines and their surrogates were observed to have different behavior[20]. Comparisons with the experimental results also found that current gasoline kinetic models[12] over predicted low temperature oxidation reactions[14, $15,19,20]$.

In this work, nine gasoline surrogates are selected to represent the FACE gasolines by varying various target properties[40]. Three of these are binary n-heptane/iso-octane mixtures with different octane numbers, while the remaining six are multi-component mixtures with five to eight 
hydrocarbons. The oxidation of FACE gasolines and their surrogates is investigated in JSR facilities. The effects of fuel octane number and hydrocarbon composition on oxidation behavior are investigated systematically, and species measurements are used to validate a gasoline surrogate chemical kinetic model. Additionally, JSR oxidation data on five real FACE gasolines, taken either from previous work $[19,20]$ (FACE A, C and F), or measured experimentally in this work (FACE I and J), are utilized to examine whether surrogate fuel kinetic modeling accurately represents real fuel behavior. Numerical simulations are conducted to help explain and investigate surrogate oxidation chemistry. The objectives of this work are to provide a comprehensive set of gasoline surrogate and real gasoline fuel oxidation data, elucidate the effects of fuel octane number and hydrocarbon composition on oxidation chemistry, and examine surrogate kinetic model predictions against real gasoline and surrogate mixture oxidation data.

\section{Experimental and computational methods}

\subsection{Gasoline properties descriptions and surrogate formations}

The FACE gasolines utilized in this work were purchased from Chevron Phillips Chemical Company LP. As stated by Cannella et al.[37], FACE gasolines were formulated by the Coordinating Research Council (CRC) to meet target values determined by the CRC Advanced, Fuel, and Lubricant (AVFL) Committee's FACE Working Group. The objective of the AVFL Working Group was to develop test fuels that facilitate researchers in evaluating fuel effects in advanced combustion engine systems. The present work on FACE gasolines provides a thorough investigation of FACE gasolines in a simplified reactor configuration, supporting the ultimate goal of developing knowledge of how gasoline fuels behave in engines. 
Detailed hydrocarbon analyses (DHA) for five FACE gasolines were performed to help in the development of surrogate mixtures. The analyses were performed at the Research and Development Center in Saudi Aramco, with standard test method ASTM D6733 and D6730. Hydrocarbons were divided into five major groups (PIONA): paraffins (n-alkanes), iso-paraffins (iso-alkanes), olefins (alkenes), naphthenes (cyclo-alkanes) and aromatics, based on their different carbon sites and carbon chain structures. Information on FACE gasolines was taken from previous literature $[14,15,38]$. Key physical and chemical properties for FACE gasolines are listed in Table 1. Detailed compositions for FACE A, C, F, I and J are in Supplementary Material-1, and their distillation curves are in Supplementary Material-2.

Table 1: Physical and chemical properties of FACE gasolines

\begin{tabular}{lcccccc}
\hline Properties & FACE A & FACE C & FACE F & FACE G & FACE I & FACE J \\
\hline RON & 83.5 & 84.7 & 94.4 & 96.8 & 70.3 & 71.8 \\
MON & 83.6 & 83.6 & 88.8 & 85.8 & 69.6 & 68.8 \\
H/C & 2.29 & 2.27 & 2.13 & 1.83 & 2.24 & 1.91 \\
MW (g/mol) & 97.8 & 97.2 & 94.8 & 99.7 & 95.45 & 100.2 \\
Density (kg/m $\left.{ }^{3}\right)$ & 685.3 & 690.5 & 707.0 & 760.0 & 688.0 & 741.0 \\
Sensitivity (=RON-MON) & -0.1 & 1.1 & 5.6 & 11.0 & 0.7 & 3.0 \\
Average molecular formula & $\mathrm{C}_{6.74} \mathrm{H}_{15.57}$ & $\mathrm{C}_{6.74} \mathrm{H}_{15.57}$ & $\mathrm{C}_{6.71} \mathrm{H}_{14.29}$ & $\mathrm{C}_{7.21} \mathrm{H}_{13.19}$ & $\mathrm{C}_{6.71} \mathrm{H}_{15.02}$ & $\mathrm{C}_{7.20} \mathrm{H}_{13.76}$ \\
\hline
\end{tabular}

Next, surrogates were formulated for target FACE gasolines. PRFs, which are binary mixtures of n-heptane and iso-octane, were first examined since they are the simplest surrogates to represent gasoline. PRF 70, 84 and 91.5 were selected to match the antiknock index $(\mathrm{AKI}=(\mathrm{RON}+\mathrm{MON}) / 2)$ 
of the different FACE gasolines. Next higher fidelity, multi-component surrogates for each real FACE gasoline were investigated because they can represent better more of the target fuel properties. A surrogate palette was chosen based on the DHA: n-butane and n-heptane to represent n-alkanes, 2-methylbutane, 2-methylhexane and iso-octane for iso-alkanes, 1-hexene for olefins; cyclo-pentane for cycloalkanes, toluene and 1,2,4-trimethylbenzene for aromatics. The majority of chemicals were purchased from Sigma Aldrich, except 2-methylhexane was purchased from ChemSampCo and n-butane was purchases from Abdullah Hashim Industrial Gases (AHG). Composition of multi-component surrogates were determined using an optimization algorithm of RON, MON, PIONA, H/C ratio, average molecular weight, density and distillation curve[40], following same methodology as in previous work[14, 20], and referred to as FGX-KAUST $(\mathrm{X}=\mathrm{A}, \mathrm{C}, \mathrm{F}, \mathrm{G}, \mathrm{I}, \mathrm{J})$ in this work. Thus, each FACE fuel had two candidates, a PRF surrogate and multicomponent surrogate (FGX-KAUST), with similar AKI but different compositions, in order to reveal octane number and composition effects on gasoline surrogate oxidation chemistry. Surrogate compositions, physical and chemical properties are provided in Table 2.

Table 2: Surrogate properties and compositions in mole fraction (FGA-, FGC-, FGF-, and FGGKAUST compositions taken from previous work $[14,20])$. RON and MON for each molecule is from CloudFlame database[41].

\begin{tabular}{lccccccccccc}
\hline Compound/ & FGA- & FGC- & FGF- & FGG- & FGI- & FGJ- & PRF & PRF & PRF \\
RON/MON & KAUST & KAUST & KAUST & KAUST & KAUST & KAUST & 70 & 84 & 91.5 \\
\hline n-butane/94/90 & 0.08 & 0.18 & 0.07 & 0.08 & 0 & 0.10 & 0 & 0 & 0 \\
2-methylbutane/92/90 & 0.12 & 0.05 & 0.10 & 0.09 & 0.11 & 0 & 0 & 0 & 0 \\
2-methylhexane/42/46 & 0.10 & 0.05 & 0.07 & 0.10 & 0.27 & 0.23 & 0 & 0 & 0 \\
iso-octane/100/100 & 0.60 & 0.55 & 0.44 & 0.18 & 0.34 & 0.12 & 0.67 & 0.82 & 0.90 \\
1-hexene/77/64 & 0 & 0 & 0.08 & 0.08 & 0.06 & 0 & 0 & 0 & 0
\end{tabular}




\begin{tabular}{|c|c|c|c|c|c|c|c|c|c|}
\hline n-heptane/0/0 & 0.10 & 0.12 & 0 & 0 & 0.12 & 0.25 & 0.33 & 0.18 & 0.10 \\
\hline Cyclopentane/100/85 & 0 & 0 & 0.16 & 0.15 & 0.06 & 0 & 0 & 0 & 0 \\
\hline Toluene/118/103 & 0 & 0.05 & 0 & 0.11 & 0.04 & 0 & 0 & 0 & 0 \\
\hline 1,2,4-trimethylbenzene/110/101 & 0 & 0 & 0.08 & 0.21 & 0 & 0.30 & 0 & 0 & 0 \\
\hline RON & 84 & 84 & 93.6 & 96.8 & 70.7 & 70.6 & 70 & 84 & 91.5 \\
\hline MON & 84 & 84 & 88.9 & 85.8 & 68.4 & 66.5 & 70 & 84 & 91.5 \\
\hline AKI & 84 & 84 & 91.3 & 91.3 & 69.6 & 68.6 & 70 & 84 & 91.5 \\
\hline $\mathrm{H} / \mathrm{C}$ & 2.29 & 2.28 & 2.12 & 1.85 & 2.21 & 1.95 & 2.26 & 2.26 & 2.25 \\
\hline MW (g/mol) & 101.5 & 98.4 & 96.2 & 94.3 & 98.9 & 103.2 & 109.7 & 112.0 & 112.9 \\
\hline Density $\left(\mathrm{kg} / \mathrm{m}^{3}\right)$ & 694 & 696 & 707 & 742 & 683 & 730 & 688 & 689 & 690 \\
\hline
\end{tabular}

\subsection{Experimental setup of jet stirred reactor}

JSR-1 experiments were performed at KAUST, Saudi Arabia. A detailed description follows. Fused silica was used to make a spherical reactor (volume $76 \mathrm{~cm}^{3}$ ) to prevent wall reactions. Four opposing nozzles (ID $0.3 \mathrm{~mm}$ ) were used as the inlets of the reactor to achieve perfect mixing by creating jet flow stirring. The mixing performance has been checked experimentally in previous work[42]. Gasoline surrogates were vaporized at $450 \mathrm{~K}$ and then diluted with nitrogen, which also functioned as a carrier gas to introduce fuel vapor into the spherical reactor through the inner capillary inlet. Diluted oxygen was introduced into the reactor through an outer quartz channel, so that oxygen and fuel would not meet until admission into the spherical reactor. A K-type thermocouple, inside the reactor, monitored reaction temperature. Temperature profiles were measured with a pure nitrogen flow and showed good uniformity (gradient $<3 \mathrm{~K} / \mathrm{cm}$ ) inside the reactor. Controlled by MKS mass flow controllers, the gas flow rates were adjusted with the reactor temperature to achieve fixed residence time inside the reactor. The gases were extracted through the tip of a quartz microprobe. Further gas reactions of the extracted gases were frozen by a 
pressure-drop in the sonic-throat gas sampling. Then the sample gas was analyzed online using two GCs (Agilent Refinery Gas Analysis (RGA) and 7890B). The Agilent RGA system, for quantifying $\mathrm{O}_{2}, \mathrm{CO}_{2}, \mathrm{CO}, \mathrm{CH}_{4}, \mathrm{C}_{2} \mathrm{H}_{4}$, etc. is a gas chromatograph configured with three parallel channels that can analyze different species simultaneously. After sample injection, analytes are divided into three columns, one is connected to a flame ionization detector (FID) and the other two to thermal conductivity detector (TCD). Light hydrocarbons from $\mathrm{C} 1$ to $\mathrm{C} 6$ are detected on the FID channel, while permanent gases are detected by a TCD. The second TCD is used for $\mathrm{H}_{2}$ detection only with $\mathrm{N}_{2}$ as reference gas. Two 10-port valves are utilized filling the sample loops and back-flushing heavier components in-lines. Three 6-port valves are used to distribute the sample to the various columns. The Agilent 7890B system was equipped with a DB-1 column to analyze 2-methylbutane, 2-methylhexane, iso-octane, n-heptane, 1-hexene, cyclopentane, toluene, 1,2,4-trimethylbenzene.

Once obtaining signals for each peak on the GC, two calculation methods were employed to convert signals to mole fractions. The first one is an internal calibration. Fuel molecules in surrogate mixtures (of known composition) were assumed to be non-reactive at $500 \mathrm{~K}$, and the detected signals were assumed to be the input mole fraction. Detected signals at other temperatures were compared with the signals at $500 \mathrm{~K}$ to determine their concentration. For other species, cold calibration gas with known composition was used to achieve GC detector response factors. Species signals at each temperature were then converted to mole fractions by comparing to the signals of calibration gas using the response factors. The second method employed is based on FID effective carbon number. For each species except $\mathrm{CO}, \mathrm{CO}_{2}, \mathrm{O}_{2}$ and $\mathrm{H}_{2}$, the FID effective carbon numbers can be found in our database, and utilized to convert absolute signal to species mole fraction. We compared the results of these two methods, and found them to be close. The uncertainty is mainly 
from GC sampling instability, which was minimized by averaging three repeated measurements at each temperature point.

JSR-1 conditions were as follows: fuel concentration at $0.5 \%$ and $0.25 \%$, pressure 1 bar, residence time $1 \mathrm{~s}$ and $2 \mathrm{~s}$, various temperatures from $500 \mathrm{~K}$ to $1050 \mathrm{~K}$ and equivalence ratios of 0.5 , 1.0, within $10 \%$ of uncertainty. Blank runs were performed before experiments to ensure no residual fuel in the system. Experiments were performed in triplicate and the average values are reported. Measurement repeatability was observed to be within $10 \%$, and uncertainty of temperature measurement was determined as $25 \mathrm{~K}$.

Surrogate samples were blended among different hydrocarbon compositions in liquid phase (purity no less than 97.0\%), while n-butane (purity 99.5\%) was introduced in gas phase and mixed in the vaporizer. The fuel concentration was kept low to eliminate excessive heat release and temperature rise during oxidation. The experimental setup scheme is presented in Scheme 1. This new experimental setup JSR-1 was validated by comparing n-heptane oxidation measurements from literature[43]. The results for JSR-1 are presented in Figure S1 in the Supplementary Material-3, and indicate that the KAUST setup is in agreement with similar setups available elsewhere, within $10 \%$ of uncertainty. 


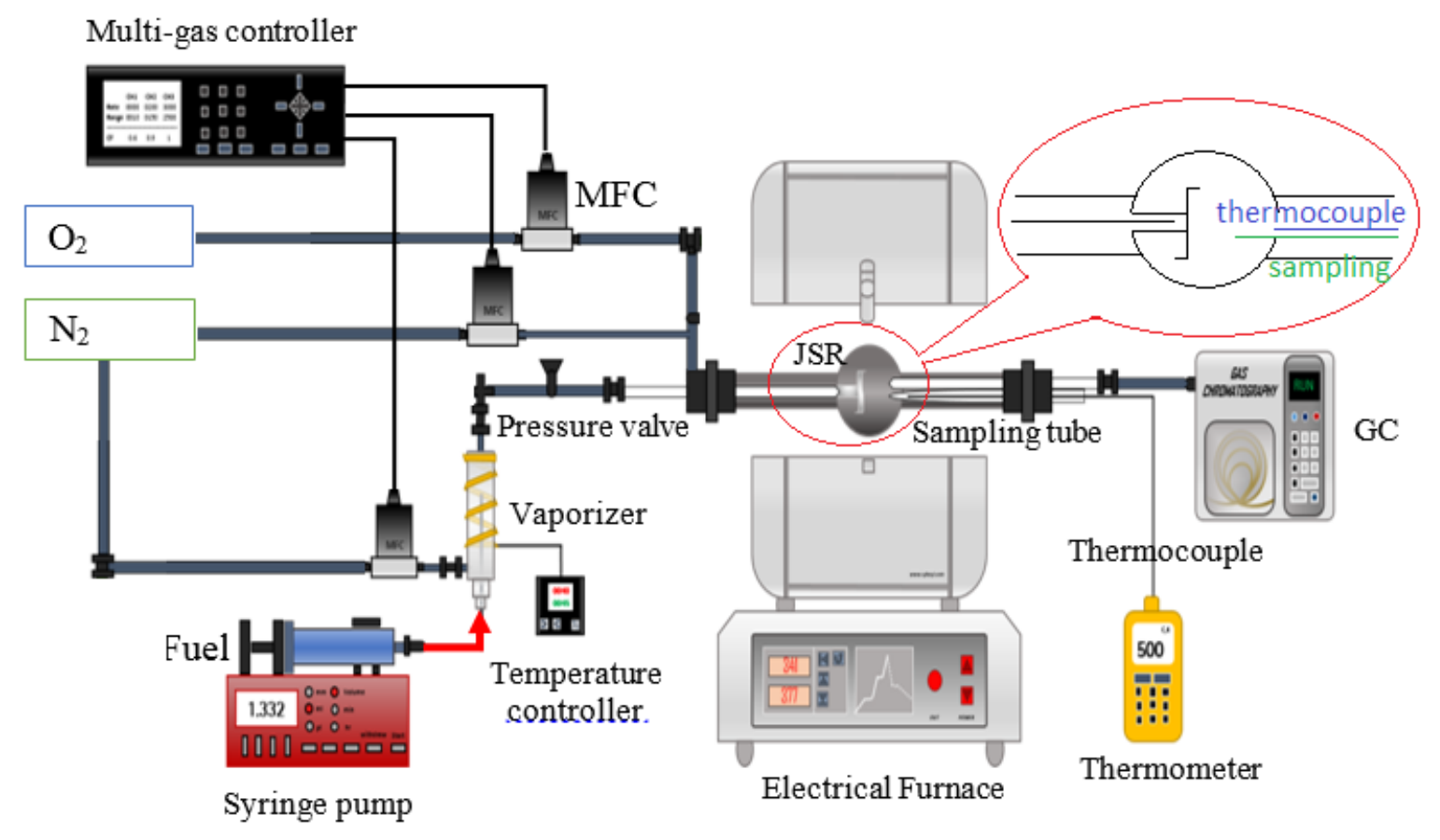

Scheme 1. Schematic of the JSR-1 setup at King Abdullah University of Science and Technology (KAUST).

JSR-2 experiments were performed in Centre National de la Recherche Scientifique (CNRS), Orleans, France. The experimental setup was similar to JSR-1; its descriptions can be found in previous work[20,44]. JSR-2 was operated at pressure nearer to those in an engine. The conditions were fuel concentration of $1000 \mathrm{ppm}$, pressure $10 \pm 0.1 \mathrm{bar}$, residence time $0.7 \pm 0.05 \mathrm{~s}$, temperatures from $530 \mathrm{~K}$ to $1250 \mathrm{~K}$ and equivalence ratios of $0.5,1.0$ and 2.0. Species mole fractions determined in experiments showed good repeatability within experimental errors of $10 \%$ and good carbon balance was also achieved. A summary on the experimental conditions of two JSRs is presented in Table 3. 
Table 3. Experimental apparatus and conditions of two JSRs with nitrogen as diluent. Experimental uncertainty is estimated as $10 \%$. (FACE A, C and F experiments in JSR-2 were performed in previous work $[19,20])$

\begin{tabular}{|c|c|c|c|c|c|c|}
\hline Apparatus & Target fuels & $\begin{array}{c}\text { Fuel } \\
\text { concentration }\end{array}$ & $\begin{array}{c}\text { Temperature } \\
(\mathrm{K})\end{array}$ & $\begin{array}{l}\text { Residence } \\
\text { time (s) }\end{array}$ & $\begin{array}{l}\text { Pressure } \\
\text { (bar) }\end{array}$ & $\phi$ \\
\hline JSR-1 & $\begin{array}{c}\text { PRF 70,84,91.5 } \\
\text { FGX-KAUST } \\
(\mathrm{X}=\mathrm{A}, \mathrm{C}, \mathrm{F}, \mathrm{G}, \mathrm{I}, \mathrm{J}) \\
\end{array}$ & $5000 \mathrm{ppm}$ & $500-750$ & 2 & $1 \mathrm{bar}$ & $0.5,1.0$ \\
\hline JSR-1 & $\begin{array}{c}\text { PRF 70,84,91.5 } \\
\text { FGX-KAUST } \\
(X=A, C, F, G, I, J)\end{array}$ & $2500 \mathrm{ppm}$ & $750-1050$ & 1 & 1 bar & 1.0 \\
\hline JSR-2 & $\begin{array}{l}\text { Real FACE } \\
\text { A,C,F,I and J } \\
\text { gasoline fuels }\end{array}$ & $1000 \mathrm{ppm}$ & $530-1200$ & 0.7 & $10 \mathrm{bar}$ & $\begin{array}{c}0.5,1.0 \\
2.0\end{array}$ \\
\hline
\end{tabular}

\subsection{Numerical gasoline surrogate kinetic modeling}

The gasoline surrogate kinetic model adopted in this work is a recently updated model[45]; the base model was developed by Mehl et al.[12], and recently updated[45]. Sub-models of $\mathrm{C}_{0}-\mathrm{C}_{4}$ hydrocarbons[46], iso-pentane[47], 2-methylhexane[48, 49], n-heptane[43], iso-octane[50], 1hexene[12], cyclopentane [51], toluene[12] and 1,2,4-trimethylbenzene reactions[14, 52] have been validated and updated, covering the entire surrogate palette. The $i s o$-octane model utilized in the gasoline surrogate model here is a modified version showing similar level of agreement that of Atef et al.[50]. Scheme S1 in Supplementary Material-3 displays structures for all species notations presented in the followed discussions.

CHEMKIN-PRO software[53] and a perfect-stirred reactor code were applied in all numerical simulations, with a transient solver at end time of 50s for converged solutions. Input of each 
surrogate for the JSR-2 was modified to meet the carbon balance with real gasoline fuels. For example, the average molecule formula of FACE I is $\mathrm{C}_{6.71} \mathrm{H}_{15.02}$, while PRF 70 is $\mathrm{C}_{7.67} \mathrm{H}_{17.35}$ and FGI-KAUST is $\mathrm{C}_{6.94} \mathrm{H}_{15.32}$. To meet the carbon balance of FACE I, instead of $1000 \mathrm{ppm}$, the input of PRF 70 and FGI-KAUST was modified to $874.4 \mathrm{ppm}$ and $966.9 \mathrm{ppm}$, respectively. The input of FGJ-KAUST (average molecule formula $\mathrm{C}_{7.46} \mathrm{H}_{14.54}$ ) was changed to $965.1 \mathrm{ppm}$ to meet FACE J carbon balance. No modifications on simulations were applied on JSR-1 surrogate simulations.

\section{Gasoline surrogate oxidation}

The oxidation of nine surrogate fuels is shown in Figs 1-3. Figures 1 and 2 show the low temperature (500-750K) behavior and Figure 3 shows the intermediate temperature behavior (7501050K). Fuel profiles were determined with experimental and numerical summation of all the surrogate components. Symbols represent experimental results and lines represent simulations.

Figures 1a and 2a compare measured and computed fuel profiles for three PRF fuels for equivalence ratios of 0.5 and 1.0, with the aim of revealing the effect of octane number on fuel oxidation chemistry. At both equivalence ratios, fuel reactivity decreased with increasing octane number. The model matches these trends, albeit agreement is better at equivalence ratio of 0.5 than at 1.0. Fuel consumption in generally initiated in the simulations about 30 to $40 \mathrm{~K}$ lower in temperature than in the experiments. This suggests that some improvements can be made in the initial reactivity of the model at low temperatures. Model analysis is performed later to point out responsible key reactions in low temperature oxidation.

Figures 1b-d, 2b-d and 3b-d compare PRF and two multi-component surrogates with similar octane numbers but different compositions; this enables us to understand the compositional effects on oxidation chemistry. Other species profiles, e.g. $\mathrm{O}_{2}, \mathrm{CO}, \mathrm{CO}_{2}, \mathrm{C}_{2} \mathrm{H}_{4}, \mathrm{C}_{3} \mathrm{H}_{6}$ and butene isomers 
are presented in the Supplementary Material-4 (low temperature) and Supplementary Material-5 (high temperature).

Two stages of oxidation were found experimentally and predicted numerically. Hydrocarbons first reacted with oxygen when the temperature was $500-600 \mathrm{~K}$, and then reactivity was reduced between 600-750K (Fig. 1 and Fig. 2); finally, oxidation increased between 800-1050K (Fig. 3). This phenomenon is called negative temperature coefficient behavior[54, 55]. The explanation for this phenomenon is that low temperature oxidation and high temperature oxidation have two different reaction mechanisms, which are both thermodynamically and/or kinetically limited in the intermediate temperature. For low octane number surrogates (e.g. FGI-KAUST and FGJ-KAUST), some reactivity was observed between 700 and $750 \mathrm{~K}$ in Figure 2c. For high octane number surrogates (e.g., FGF-KAUST and FGG-KAUST), no reactivity was found between temperatures of $500-800 \mathrm{~K}$ and at an equivalence ratio of 1.0 . 


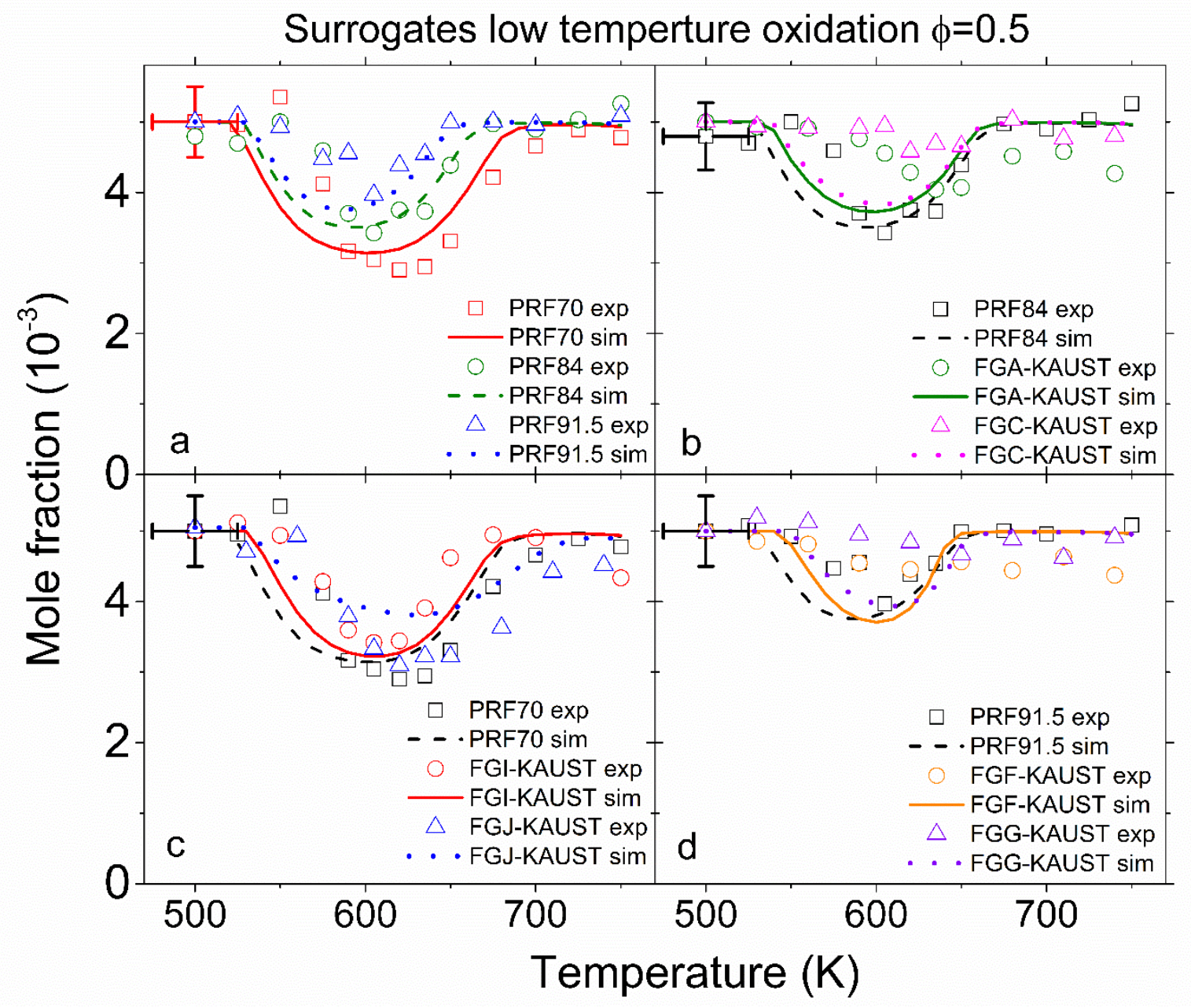

Figure 1: Low temperature oxidation $(500-750 \mathrm{~K})$ fuel profiles for nine selected surrogates. Experimental data from JSR-1 and numerical simulation $(\phi=0.5)$. 


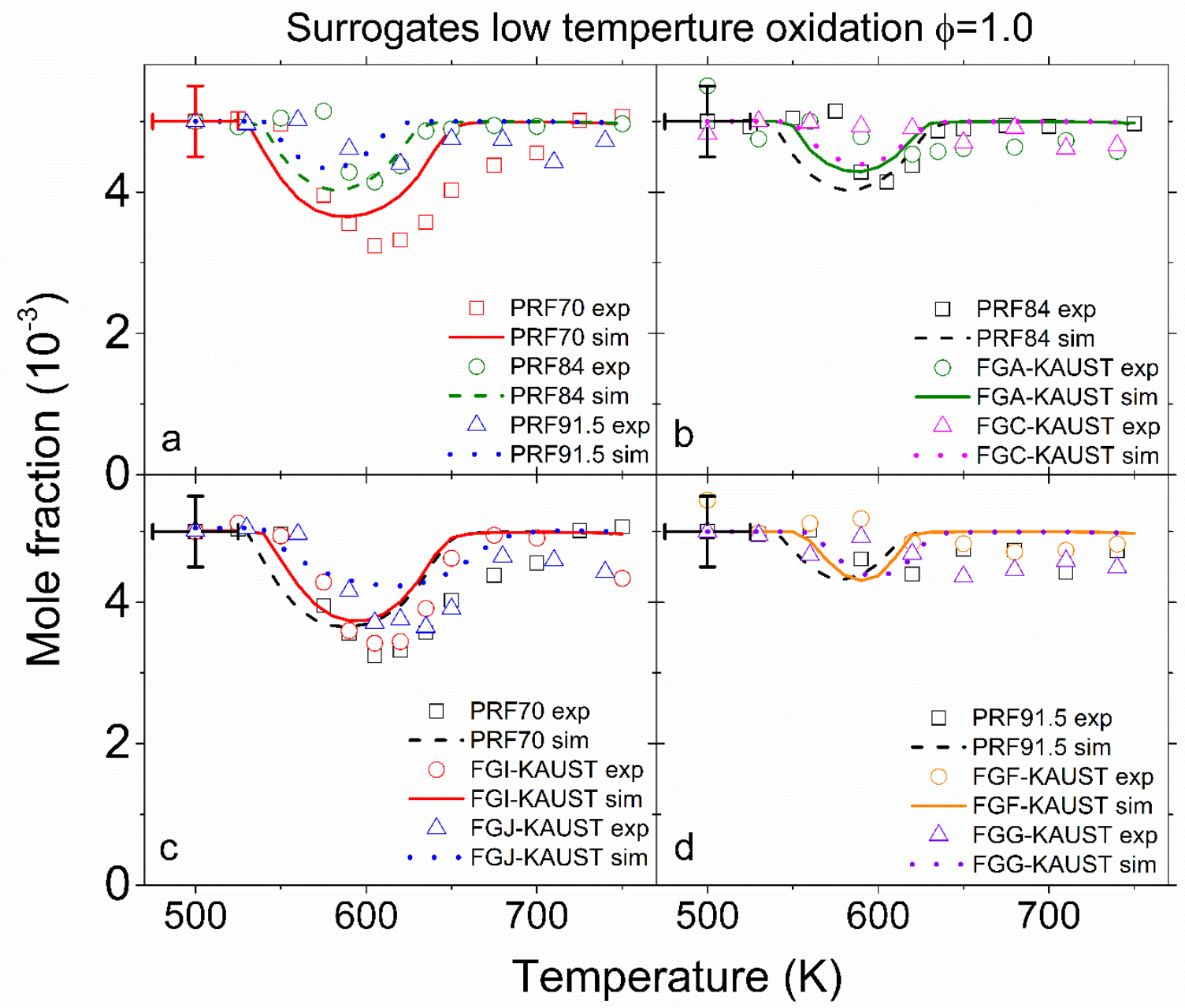

Figure 2: Low temperature oxidation $(500-750 \mathrm{~K})$ fuel profiles for nine selected surrogates. Experimental data from JSR-1 and numerical simulation $(\phi=1.0)$. 


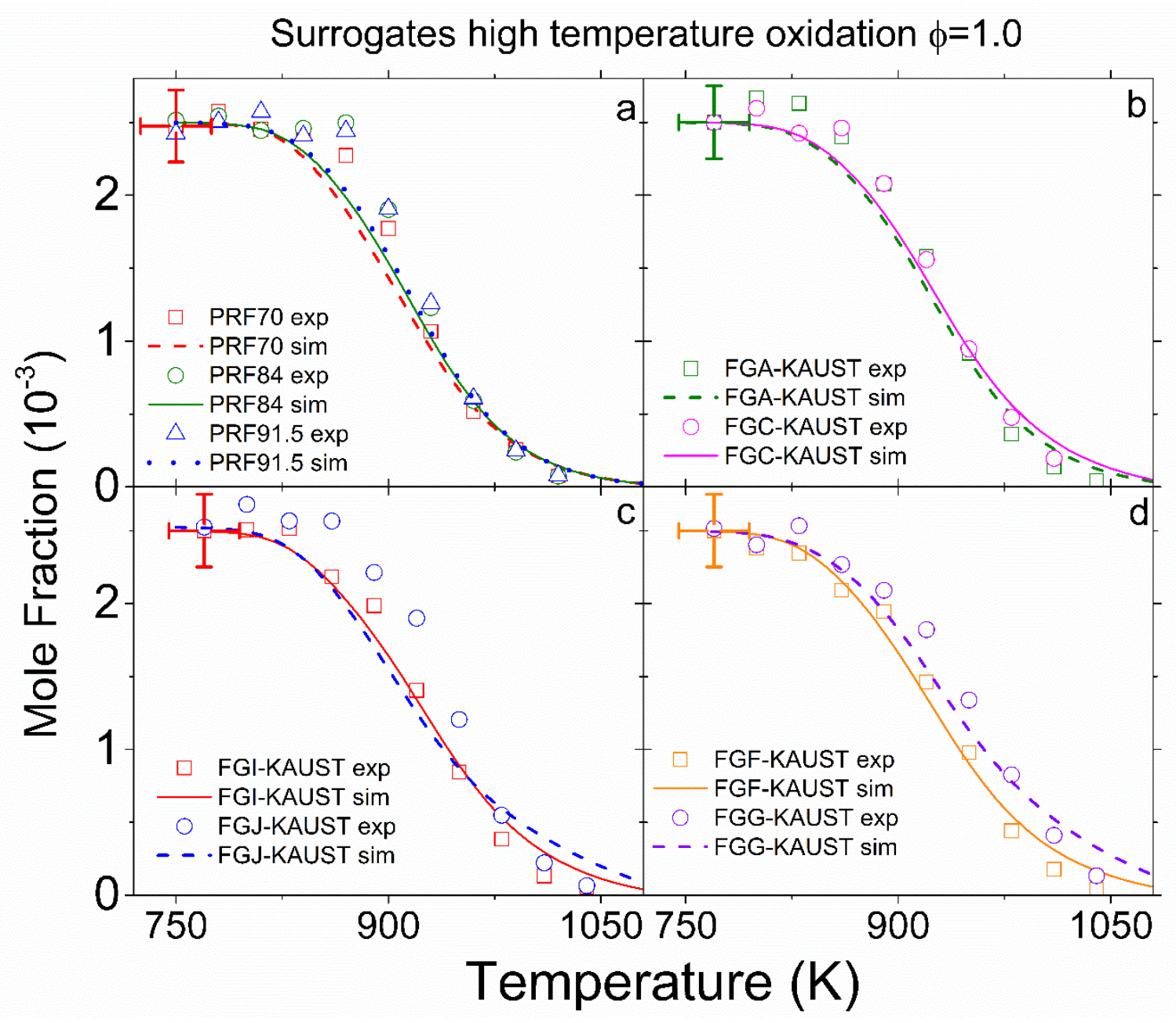

Figure 3: High temperature oxidation (750-1050K) fuel profiles for nine selected surrogates. Experimental data from JSR-1 and numerical simulation $(\phi=1.0)$.

\subsection{Low temperature oxidation}

Low temperature oxidation is important for governing the anti-knock quality of fuels in spark ignition internal combustion engines[56] and ignition delay in compression ignition . Therefore, it is necessary to investigate low temperature oxidation chemistry.

A comprehensive detailed low temperature oxidation $(500-750 \mathrm{~K})$ scheme has been given by Battin-Leclerc et al. [57]. A brief description of alkane low temperature oxidation reaction 
pathways is presented here. When the temperature is between $550-650 \mathrm{~K}$, hydrogen abstraction from large alkane molecules $(\mathrm{RH})$ forms large alkyl radicals $(\mathrm{R} \cdot)$, which then react with oxygen to form an alkyl peroxide radicals (ROO·). Intramolecular hydrogen migration occurs next through a five- to eight-membered transition state rings, producing another carbon centered radical $(\cdot \mathrm{QOOH})$. A second $\mathrm{O}_{2}$ addition proceeds resulting to form an $\cdot \mathrm{OOQOOH}$ radical. Theoretically, more oxygen addition reactions could occur[58], but the most favorable reaction pathway for $\cdot \mathrm{OOQOOH}$ is intramolecular hydrogen migration to $\mathrm{HOOQ}{ }^{\prime} \mathrm{OOH}$, and then decomposition to form keto-hydroperoxide $\left(\mathrm{HOOQ}^{\prime}=\mathrm{O}\right)$ and release of $\mathrm{OH}$. This is the most important reaction in low temperature oxidation, since it can release $\mathrm{OH}$ radicals and keto-hydroperoxides, which further decompose and produce more $\mathrm{OH}$ radicals. This reaction is a key chain branching step promoting low temperature oxidation. When temperature increases (e.g., 650-750K), the large oxygenated radical intermediates (e.g., ROO· and $\cdot \mathrm{QOOH}$ ) can overcome energy barriers for dissociation, molecular elimination reactions forming alkenes and less reactive $\mathrm{HO}_{2}$ radicals, and cyclization reactions forming cyclic ethers and $\mathrm{OH}$ radicals. These pathways produce less reactive products than the aforementioned chain branching pathway. Thus, in intermediate temperature region (e.g., 650-750K), the concentration of important radicals (i.e., OH) is reduce and the overall rate of fuel consumption is slowed.

Compared to n-alkanes, some hydrocarbons, such as iso-octane[50], cyclopentane[51] and toluene[59] have weak low temperature reactivity because their structures do not facilitate rapid peroxy radical isomerization reactions that lead to chain branching keto-hydroperoxides . Gasoline surrogates and real gasoline fuels are mixtures of both reactive components (e.g. n-alkanes) and non-reactive components (e.g. highly-branched alkanes, cyclopentanes, alkenes and aromatics). In the next sub-sections, experimental and numerical investigations are discussed on PRF surrogates 
with different octane numbers and multicomponent surrogates with different hydrocarbon compositions, in order to reveal the effects of octane number and composition on low temperature oxidation behavior. These comparisons also evaluate model predictions for the PRF surrogates and the multi-component surrogates against experimental measurements of the same mixtures.

\subsubsection{Effect of surrogate octane number}

Experimental and numerical investigations of three selected PRFs are presented in Figs. 1a and 2a under two equivalence ratios ( $\phi=0.5$ and 1.0). It is clearly shown that all three PRFs exhibit low temperature oxidation behavior under selected conditions. Of the three PRFs, PRF 70 exhibits the highest reactivity, followed by PRF 84 and PRF 91.5. Numerical simulations show similar reactivity, however the simulated start of reactivity was 30 to $40 \mathrm{~K}$ before the measured start reactivity (recall the temperature uncertainty is $25 \mathrm{~K}$ ).

The three PRFs have identical hydrocarbon components--n-heptane and iso-octane--albeit with different concentrations. As illustrated in previous literature[50, 60], n-heptane $(\mathrm{RON}=\mathrm{MON}=0)$ exhibits low temperature oxidation behavior while iso-octane $(\mathrm{RON}=\mathrm{MON}=100)$ does not. The observed oxidation trends in the JSR experiments are reasonable because low octane number PRFs with more n-heptane are more reactive than high octane number PRFs with high concentration of iso-octane [23, 61, 62]. In PRF oxidation, n-heptane oxidation happens first, producing $\mathrm{OH}$ radicals and keto-hydroperoxides. Keto-hydroperoxides further decompose to produce additional $\mathrm{OH}$ radicals. Highly reactive $\mathrm{OH}$ radicals can abstract hydrogen from nonreactive iso-octane, thereby initiating its low temperature oxidation reactions. Recent engine experiments showed similar behavior of different PRF compositions on two-stage heat release characteristics[63]. Similar results of oxidation of one reactive component activating the oxidation of another less reactive component have been observed in n-heptane/ethanol[64] and 
toluene/dimethyl ether[65] mixtures. With increased n-heptane, the overall octane number decreases and more $\mathrm{OH}$ can be produced through n-heptane oxidation reactions. Thus, lower octane number PRFs exhibit greater low temperature reactivity. To conclude, PRFs with lower octane numbers are more reactive under low temperature oxidation conditions. A further deduction is that other multi-component surrogates and real gasoline fuels with lower octane number can be expected to exhibit greater low temperature oxidation. Further evidence to support this postulation is presented in the following sections.

\subsubsection{Effect of surrogate composition}

Experimental and numerical investigations on nine selected surrogates are presented in Figs. $1 b-d$ and $2 b-d$ under two selected equivalence ratios $(\phi=0.5$ and 1.0). Fuel profiles of three surrogates with similar octane numbers are included in the same graphs for comparison. $\mathrm{CO}, \mathrm{CO}_{2}$ and $\mathrm{O}_{2}$ profiles are included in Figure S2-S7 in Supplementary Material-3. Each group of three surrogates with similar AKI have different compositions in order to reveal compositional effect on low temperature oxidation.

In each surrogate fuel group, PRFs were experimentally observed to be the most reactive. Amongst multi-component surrogates with similar octane number, surrogates with more lowoctane number (e.g., n-alkanes) components exhibited higher reactivity (e.g., FGA-KAUST was more reactive than FGC-KAUST). Another finding is that the aromatic-rich surrogate for FGJKAUST has closer reactivity to PRF than the alkane-rich surrogate for FGI-KAUST. This can be explained by the same theory that FGJ-KAUST has more low-octane number components, e.g. nheptane, than FGI-KAUST. Despite the large amount of aromatics in FGJ-KAUST, more nalkanes in its composition makes it more reactive in the low temperature region. Some multicomponent surrogates (FGF-KAUST and FGG-KAUST) showed little low temperature reactivity. 
This can be expected since there is no $n$-heptane in FGF-KAUST and FGG-KAUST, which is needed to initiate low temperature reactivity. However, numerical simulations failed to reproduce this behavior, indicating current kinetic model requires further investigation. $\mathrm{CO}, \mathrm{CO}_{2}$ and $\mathrm{O}_{2}$ profiles provided further support for these observations and conclusions. In summary, when comparing surrogate fuel mixtures of similar octane number, those with more low-octane number components are expected to have higher reactivity in low temperature oxidation under the conditions explored in JSR-1. Future work should focus on performing similar experiments at higher pressures and a broader range of residence times and equivalence ratios to further corroborate our findings.

\subsubsection{Sensitivity and rate of production analysis}

Model analysis was performed in this section to reveal key reactions that could promote or inhibit fuel reactivity. Target surrogates were chosen as PRF 70, FGI-KAUST and FGJ-KAUST due to their strong low temperature reactivity. Analysis was performed at $620 \mathrm{~K}$, corresponding to the temperature with the strongest low temperature oxidation reactions. Rate of production analysis was conducted first to reveal main fuel consumption reaction pathways. Detailed results are presented in Supplementary Material-6. Scheme S1 in Supplementary Material-3 presents nomenclatures for species discussed in the following text. Top ten $\mathrm{OH}$ consumption and production reaction pathways are presented in Figure 4. Primary $\mathrm{OH}$ consumption reactions are $\mathrm{H}$-atom abstraction reactions by $\mathrm{OH}$ radical, as proved in various hydrocarbon oxidation chemistry studies[43]. Hydrogen abstraction reactions of iso-octane and 1,2,4-trimethylbenzene have large participations among $\mathrm{OH}$ consumption channels, which consists with proposed low temperature reaction scheme. $\mathrm{OH}$ radical produced by n-heptane low temperature reactions can further abstract hydrogen from iso-octane and 1,2,4-trimethylbenzene and initiate their low temperature reactions. 


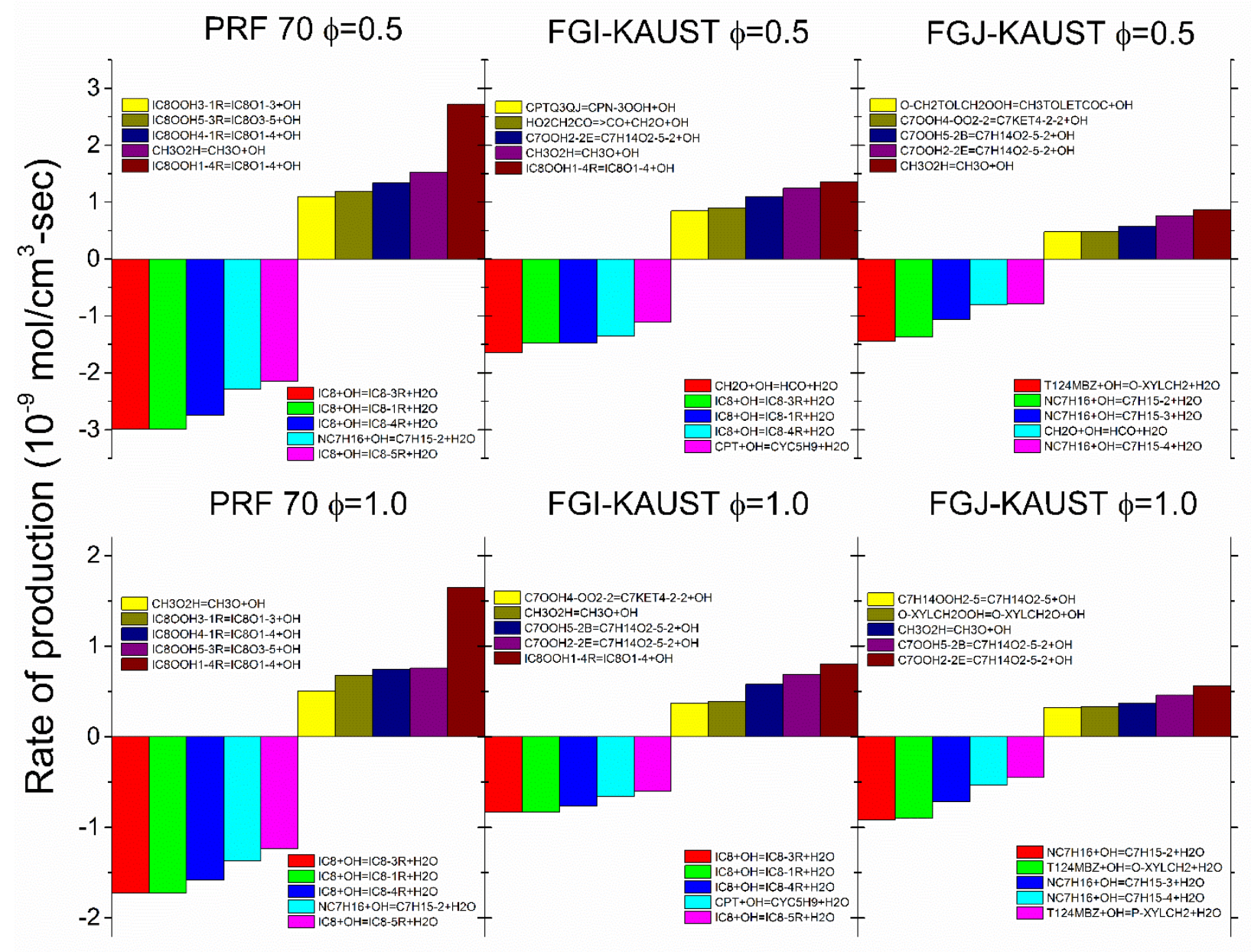

Figure 4: Top ten $\mathrm{OH}$ consumption and production reactions on three selected gasoline surrogates (PRF 70, FGI-KAUST and FGJ-KAUST) simulations at 620K under two conditions, $\phi=0.5$ and $\phi=1.0$.

Sensitivity analysis was performed to reveal the most influential reactions in low temperature oxidation. $\mathrm{OH}$ was selected as the reactivity indicator because it is considered to be the most important radical in low temperature oxidation. The analysis was performed using Chemkin sensitivity analysis tools in the PSR reactor model[53]. The chosen temperature was $620 \mathrm{~K}$ and results are shown in Fig. 5. Nomenclatures for species mentioned in sensitivity analysis are provided in Scheme S1 in Supplementary Material-3. A negative value means that the reactions 
inhibited low temperature oxidation, while positive value indicates that the reactions promoted low temperature reactivity. $n$-Heptane reactions are marked in red and appear in italics, iso-octane reactions are blue and bold, and 1,2,4-trimethylbenzene reactions are olive green and underlined. The top promoting reactions were found to be $\mathrm{H}$-atom abstraction from low-octane number component, e.g. n-heptane and 2-methylhexane, while the most inhibiting reactions were high octane number component hydrogen abstraction reactions, e.g. iso-octane and 1,2,4trimethylbenzene. Small molecule reactions had only minor participation among the top ten sensitive reactions. These results indicate that low temperature oxidation chemistry is largely dependent on fuel molecule reaction pathways. Fuels with a greater content of low-octane number component swill exhibit greater low temperature reactivity because reactive molecules are needed to initiate the oxidation of the remaining components. 

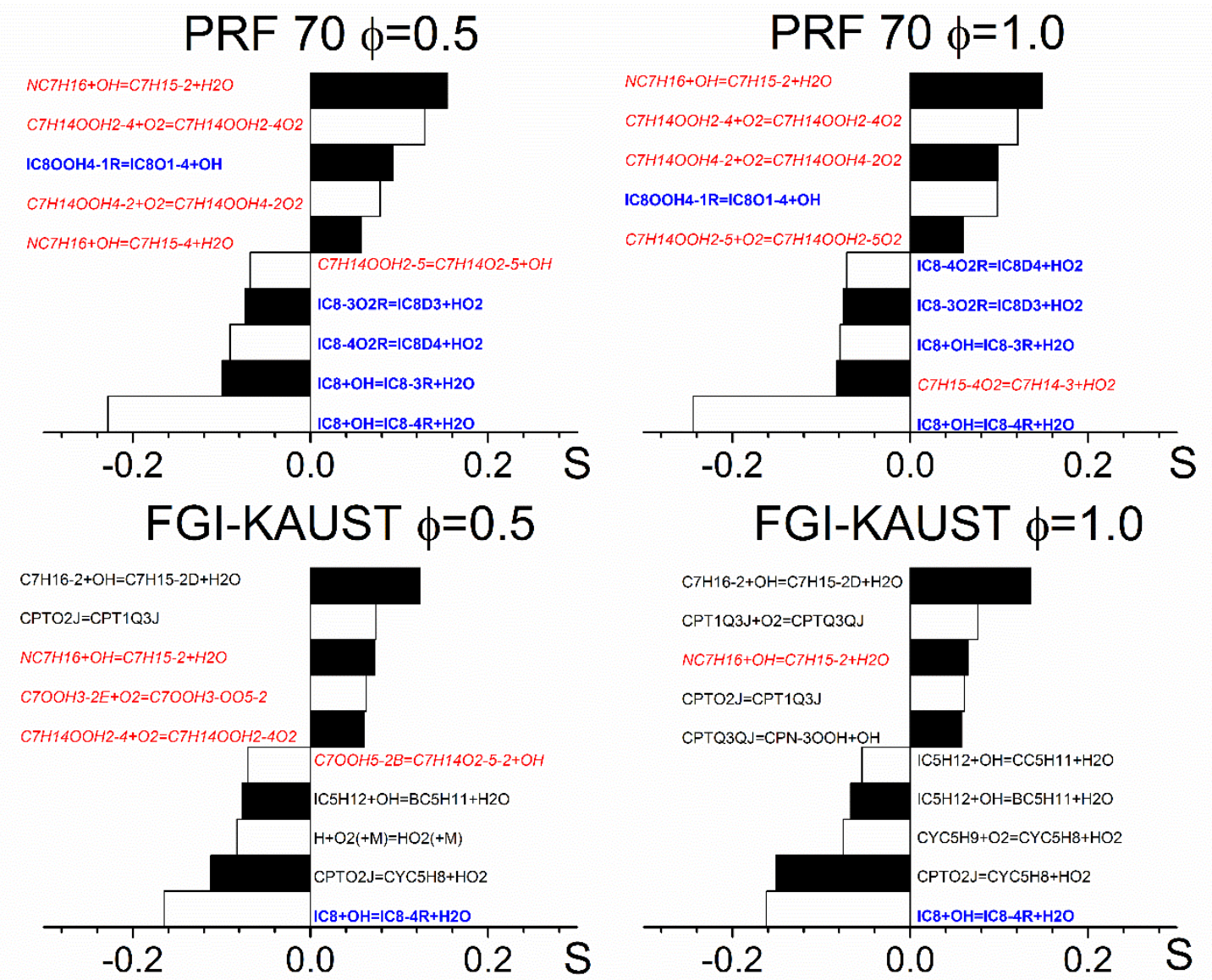

FGJ-KAUST $\phi=0.5$
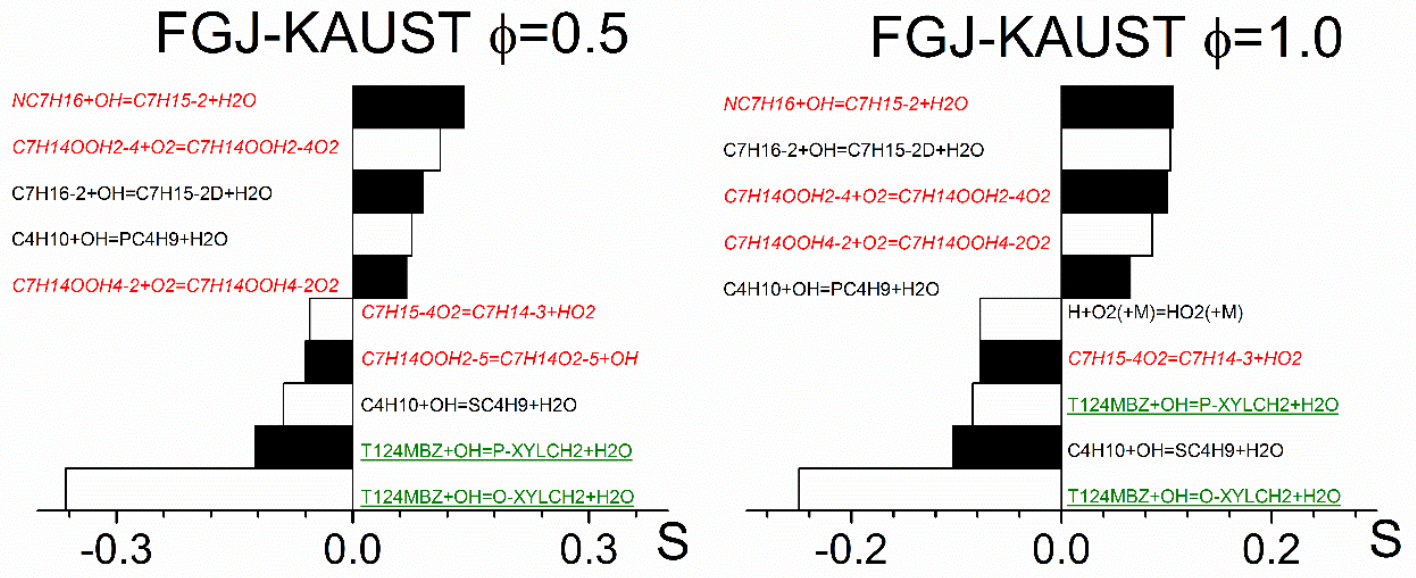

Figure 5: Normalized sensitivity coefficient of top ten $\mathrm{OH}$ reactions on three selected gasoline surrogates (PRF 70, FGI-KAUST and FGJ-KAUST) simulations at 620K under two conditions, $\phi=0.5$ and $\phi=1.0$. 


\subsection{High temperature oxidation}

High temperature oxidation of gasoline fuels affects engine stability and energy efficiency, as the major energy release in combustion occurs through high temperature oxidation chemistry. Furthermore, pollutants such as alkenes, oxygenates and soot can be produced via high temperature oxidation[1]. To understand and control these pollutants, high temperature chemistry is investigated.

Next the intermediate to high temperature $(750-1050 \mathrm{~K})$ oxidation of the surrogate fuels is discussed. Experimental and numerical investigation results for the nine selected surrogates are presented in Fig. 3, while $\mathrm{CO}, \mathrm{CO}_{2}$ and $\mathrm{O}_{2}$ profiles are provided in Figure $\mathrm{S} 8-\mathrm{S} 10$ in Supplementary Material-3. Figure 3a shows that all three PRFs have similar fuel profiles and reactivity to within experimental uncertainty, indicating the negligible effect of octane number on the oxidation chemistry in this temperature region. Figure $3 \mathrm{~b}$ compares two alkane-rich multicomponent surrogates, FGA-KAUST and FGC-KAUST. Despite composition differences, similar reactivity is again found in their fuel reactivity profiles, showing that n-alkane and iso-alkane distribution has little effect on high temperature oxidation in the JSR. Figure 3c compares two multi-component surrogates, cyclopentane-rich FGF-KAUST and toluene-rich FGG-KAUST. Experimentally and numerically, aromatic-rich FGG-KAUST showed lower reactivity than alkane-rich FGF-KAUST. This behavior is consistent with the lower reactivity of toluene compared to cyclopentane. Meanwhile, two multi-component surrogates, alkane-rich FGIKAUST and aromatic-rich FGJ-KAUST are also compared in Figure 3d. Aromatic-rich FGJKAUST showed similar high temperature reactivity with alkane-rich FGI-KAUST. FGJ-KAUST has similar amount of aromatics with FGG-KAUST, but without toluene in its composition. This indicates that 1,2,4-trimethylbenzene has similar reactivity compared to alkanes in the high 
temperature region. Similar observations and conclusions can be supported by $\mathrm{CO}, \mathrm{CO}_{2}$ and $\mathrm{O}_{2}$ profiles. It can be concluded that octane number and composition has little effect on high temperature oxidation behavior of fuels, except for the toluene-rich surrogate due to the low reactivity of toluene.

\section{Real gasoline fuel oxidation}

In the final segment of this paper, experimental results are presented on the oxidation of real FACE gasolines (A, C, F, I and J) and compared to simulation of these gasolines using the surrogate fuels previously discussed. Experimental results on FACE fuels A, C, and F were available from previous work[19, 20].

Experiments on FACE I and J experiments were conducted following the same methodology. The selected FACE fuels covered a wide range of fuel properties and compositions from low octane number (FACE I and $\mathrm{J},(\mathrm{RON}+\mathrm{MON}) / 2=70)$, medium octane number (FACE A and $\mathrm{C}$, $(\mathrm{RON}+\mathrm{MON}) / 2=84)$ to high octane number $(\mathrm{FACE} F,(\mathrm{RON}+\mathrm{MON}) / 2=91.5)$, as well as alkane-

rich gasoline fuels (FACE A, C and I), naphthene-rich gasoline fuels (FACE F) and aromatic-rich gasoline fuels (FACE J).

\subsection{Species identification}

In FACE I and $\mathrm{J}$ oxidation, over 50 species were identified and quantified experimentally in a JSR-2 at 10 atm. Major products were $\mathrm{H}_{2} \mathrm{O}, \mathrm{CO}, \mathrm{CO}_{2}$ and $\mathrm{H}_{2}$. Oxygenates, e.g. aldehydes (formaldehyde and acetaldehyde), alcohol (methanol), ketones (acetone and 2-butanone), and ketene were observed and quantified. Other important intermediates in oxidation are linear and branched alkenes, such as ethylene, propene, isobutene, 1-butene, cis- and trans-2-butene, 1pentene, cis- and trans-2-pentene and 1,3-butadiene. Detailed experimental data of all species are 
included in the Supplementary Material-7. Detailed experimental data of FACE A, C and F can be found in previous literature[19, 20].

Species with maximum concentration over $10 \mathrm{ppm}$ were identified as important intermediates and compared with gasoline surrogate kinetic model simulations. Comparisons between real fuel experiments with surrogate simulations were conducted using temperature versus mole fraction profiles. In the following sections, first the fuel profiles are discussed and then the intermediate species profiles.

\subsection{Fuel profiles}

Five FACE fuel profiles and their corresponding surrogate simulation results are shown in Fig. 6. Fuel profiles are achieved by summing up all fuel components detected experimentally, and the fuel molecules in corresponding surrogates for simulations. Again, to exclude the difference of input due to carbon balance, simulated fuel profiles are normalized to $1000 \mathrm{ppm}$ and compared with experimental data. Real gasoline experimental data are shown as scattered points, while surrogate simulation results are presented as lines. Different scattered shapes, line styles and colors distinguish the fuel oxidation results, experimentally and numerically.

Two stages of oxidation regimes, one at low temperatures (500-700K) and another at intermediate to high temperatures (700-1200K), were again observed experimentally and predicted numerically, consistent with surrogate oxidation results in the previous section. Some discrepancies between experiments and simulations were observed (e.g. FACE F fuel profiles were over-predicted in low temperature region). However, most of the surrogate simulation results accurately reproduced fuel profiles and oxidation behaviors, proving that a gasoline surrogate kinetic models can successfully mimic real gasoline fuel behavior within a wide range of 
experimental conditions and for a variety of gasoline fuels. These experimental validations show that the gasoline surrogate kinetic model is a successful, comprehensive, viable and powerful approach for simulating gasoline engines operating under different conditions and grade gasoline fuels.

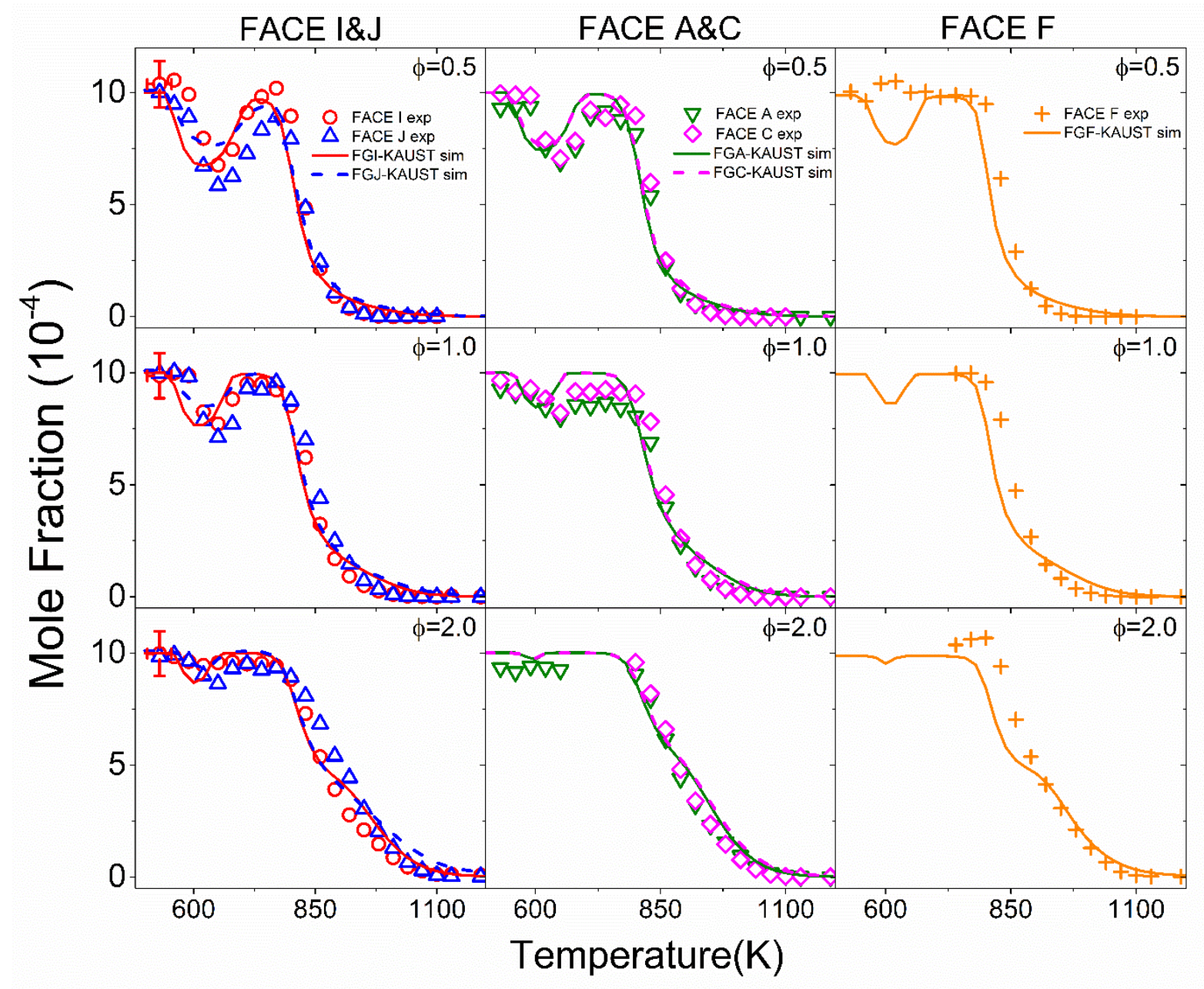

Figure 6: Fuel profiles of five FACE gasoline oxidations and their proposed surrogate simulations under three equivalence ratios $(\phi=0.5,1.0$ and $2.0 ; 10 \mathrm{~atm})$. 


\subsection{Species profiles}

To further examine gasoline surrogate kinetic model, species profiles from FACE gasoline oxidation were provided as additional evidence. Major and key intermediate species profiles of FACE I and J oxidations were measured by JSR-2, while experimental data for species profiles of FACE A, C and F are taken from literatures [19, 20]. Major and key intermediate species profiles are presented in Figure 7 and 8 under lean condition, and compared with two surrogate model simulations. Results under stoichiometry and rich conditions are included in Figure S11-14 in Supplementary Material-3. All simulated species mole fraction data using updated model in this work are included in the Supplementary Material-8. As previously mentioned, species with maximum concentration over $10 \mathrm{ppm}$ were considered important and were therefore chosen for further analysis. Eight species were selected to represent different organic compounds in gasoline oxidation. $\mathrm{H}_{2} \mathrm{O}, \mathrm{CO}, \mathrm{CO}_{2}, \mathrm{H}_{2}$ are major products of oxidation; $\mathrm{CH}_{4}$ for small alkanes, $\mathrm{CH}_{2} \mathrm{O}$ for aldehydes, $\mathrm{C}_{2} \mathrm{H}_{4}$ and $\mathrm{C}_{3} \mathrm{H}_{6}$ for alkenes. Detailed experimental data of species profiles in FACE I and $\mathbf{J}$ oxidations are included in the Supplementary Material-7. Detailed species profiles of FACE $\mathrm{A}, \mathrm{C}$ and $\mathrm{F}$ are presented and examined in the available literature $[19,20]$.

For all five FACE gasolines, the differences between experimental data and corresponding surrogate simulations for major products and important intermediates, such as $\mathrm{H}_{2} \mathrm{O}, \mathrm{CO}, \mathrm{CO}_{2}, \mathrm{H}_{2}$, and $\mathrm{CH}_{2} \mathrm{O}$, are within the limits of acceptable experimental error $(\sim+/-10 \%)$ over the entire temperature region. Small hydrocarbons such as $\mathrm{CH}_{4}, \mathrm{C}_{2} \mathrm{H}_{4}$, and $\mathrm{C}_{3} \mathrm{H}_{6}$ are predicted within uncertainty of a factor of two. It is also found that simple binary PRF surrogate can well predict selected species profiles as well as multi-component surrogates in both low and high temperature regions. By these comparisons, it can be concluded that surrogate kinetic modeling can successfully predict real gasoline fuel behaviors. Future work should perform surrogate mixture 
experiments in JSR-2 under same condition as FACE gasolines to further validate the surrogate kinetic model.

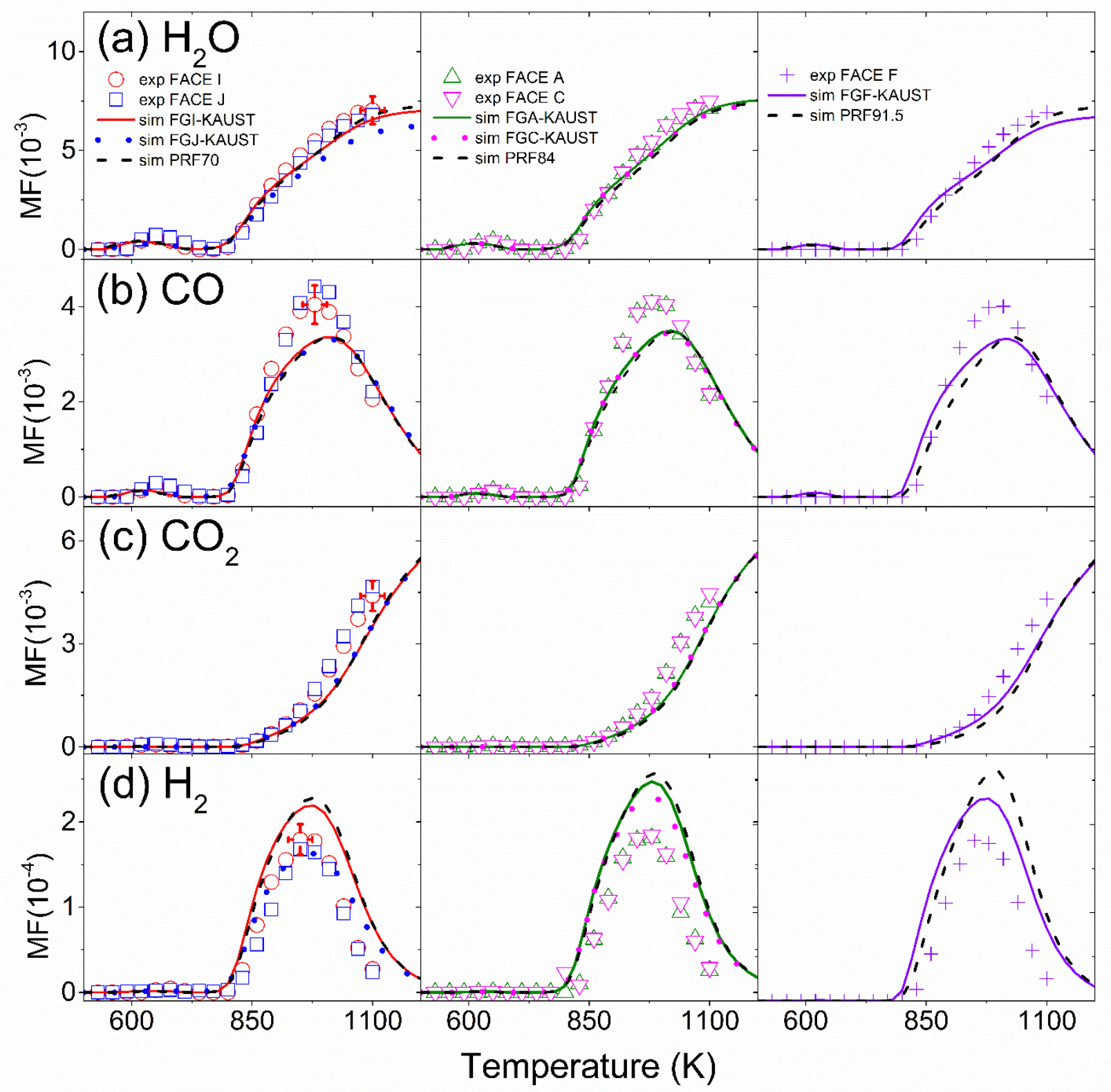

Figure 7: Major species profiles of FACE gasolines by JSR-2, with corresponding surrogate simulations, under fuel-lean conditions ( $\phi=0.5,10 \mathrm{~atm})$. 


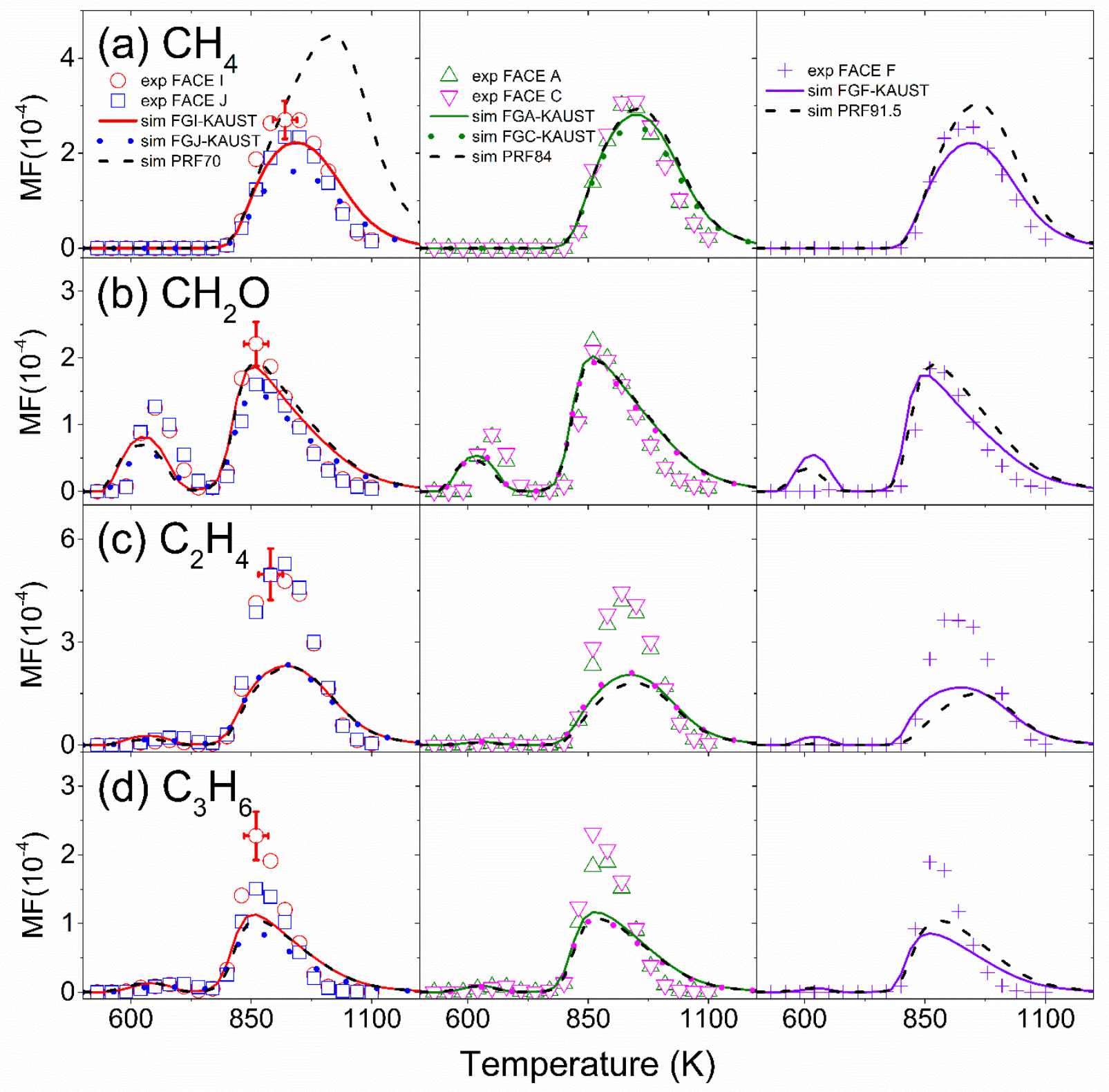

Figure 8: Key intermediate species profiles of FACE gasolines by JSR-2, with corresponding surrogate simulations, under fuel-lean conditions $(\phi=0.5,10 \mathrm{~atm})$.

\section{Conclusions}

In this work, nine gasoline surrogates and five real FACE gasoline fuels were examined experimentally and numerically under JSR conditions. These gasoline surrogates included three 
PRFs and six multicomponent surrogates to match the target FACE fuels. The PRF fuels were chosen to elucidate the effect of fuel octane number on reactivity in the JSR; the multicomponent surrogates were chosen to match the target fuels with higher fidelity than a PRF, and also to reveal compositional effects on JSR oxidation. It was found, both experimentally and numerically, that lower octane number fuel mixtures were more reactive. When comparing fuel mixtures of similar octane number, those containing more low-octane number components were found to be more reactive in the low temperature region. The importance of n-alkanes in driving the low temperature reactivity oxidation of surrogate mixtures was highlighted. Discrepancies between experiments and simulations require further investigation of the surrogate kinetic model.

In high temperature region, the influence of octane number and composition on surrogate oxidation was reduced. All surrogates showed similar reactivity, despite their different octane numbers and hydrocarbon compositions, except for toluene-rich surrogate which showed decreased high temperature reactivity. Numerical simulations accurately reproduced alkane-rich and aromatic-rich surrogates, indicating that different types of hydrocarbons share similar high temperature oxidation chemistry.

To examine the surrogate kinetic model, oxidation of five real FACE gasolines was performed in this work or obtained from data in the available literature. These five FACE gasolines included a variety of gasoline fuels with a wide octane number range and compositional differences. Surrogate simulations successfully reproduced real gasoline oxidation behavior, demonstrating that gasoline surrogate kinetic models to be a comprehensive and viable approach to simulating gasoline oxidation in real gasoline engine operation and design. Species profiles provided further confirmation of this conclusion. Future work should perform FACE gasoline and surrogate mixture experiments at a broader range of JSR conditions (e.g., higher pressures, various equivalence ratios 
and residence times, etc.), as well as investigate real fuels and surrogates in other facilities (flow reactors, shock tubes, rapid compression machines, laminar flames, etc.).

\section{Acknowledgements}

This work is supported by King Abdullah University of Science and Technology (KAUST) and Saudi Aramco under the FUELCOM program, and by the European Research Council under the European Community's Seventh Framework Programme (FP7/2007-2013) / ERC grant agreement No. 291049 - 2G-CSafe. The work at LLNL was performed under the auspices of the U.S. Department of Energy (DOE) by Lawrence Livermore National Laboratory under Contract DE-AC52-07NA27344 and was conducted as part of the Co-Optimization of Fuels \& Engines (Co-Optima) project sponsored by the DOE Office of Energy Efficiency and Renewable Energy (EERE), Bioenergy Technologies and Vehicle Technologies Offices.

\section{References}

1. Sarathy SM, Farooq A, Kalghatgi GT. Recent progress in gasoline surrogate fuels. Prog Energ Combust Sci 2018;65:67-108.

2. U.S. Energy Information Administration. International energy outlook 2016, Washington, 2016.

3. OPEC Secretariat. World oil outlook, Vienna, 2015.

4. Kalghatgi GT. The outlook for fuels for internal combustion engines. Int J Engine Res 2014;15:383398.

5. Kalghatgi G, Gosling C, Wier MJ. Petrol Technol Q 2016;23-31.

6. Ferguson $\mathrm{CR}$, Kirkpatrick AT, Internal combustion engines: applied thermosciences. 2nd ed. New York: John Wiley \& Sons; 2015.

7. Bielaczyc $P$, Woodburn J, Szczotka A. An assessment of regulated emissions and $\mathrm{CO} 2$ emissions from a European light-duty CNG-fueled vehicle in the context of Euro 6 emissions regulations. Appl Energy 2014;117:134-141.

8. Kohse - Höinghaus K, Oßwald P, Cool TA, Kasper T, Hansen N, Qi F, et al. Biofuel combustion chemistry: from ethanol to biodiesel. Angew Chem Int Ed 2010;49:3572-3597.

9. Fihri A, Mahfouz R, Shahrani A, Taie I, Alabedi G. Pervaporative desulfurization of gasoline: A review. Chem Eng Process 2016;107:94-105.

10. Drake MC, Haworth DC. Advanced gasoline engine development using optical diagnostics and numerical modeling. Proc Combust Inst 2007;31:99-124.

11. Kalghatgi GT. Developments in internal combustion engines and implications for combustion science and future transport fuels. Proc Combust Inst 2015;35:101-115. 
12. Mehl M, Pitz WJ, Westbrook CK, Curran HJ. Kinetic modeling of gasoline surrogate components and mixtures under engine conditions. Proc Combust Inst 2011;33:193-200.

13. Kukkadapu G, Kumar K, Sung C-J, Mehl M, Pitz WJ. Experimental and surrogate modeling study of gasoline ignition in a rapid compression machine. Combust Flame 2012;159:3066-3078.

14. Sarathy SM, Kukkadapu G, Mehl M, Javed T, Ahmed A, Naser N, et al. Compositional effects on the ignition of FACE gasolines. Combust Flame 2016;169:171-193.

15. Sarathy SM, Kukkadapu G, Mehl M, Wang W, Javed T, Park S, et al. Ignition of alkane-rich FACE gasoline fuels and their surrogate mixtures. Proc Combust Inst 2015;35:249-257.

16. Mannaa O, Mansour MS, Roberts WL, Chung SH. Laminar burning velocities at elevated pressures for gasoline and gasoline surrogates associated with RON. Combust Flame 2015;162:2311-2321.

17. Selim H, Mohamed SY, Dawood AE, Sarathy SM. Understanding premixed flame chemistry of gasoline fuels by comparing quantities of interest. Proc Combust Inst 2017;36:1203-1211.

18. Selim H, Mohamed SY, Hansen N, Sarathy SM. Premixed flame chemistry of a gasoline primary reference fuel surrogate. Combust Flame 2017;179:300-311.

19. Chen B, Togbé C, Selim H, Dagaut P, Sarathy SM. Quantities of Interest in Jet Stirred Reactor Oxidation of a High-Octane Gasoline. Energy Fuels 2017;31:5543-5553.

20. Chen B, Togbé C, Wang Z, Dagaut P, Sarathy SM. Jet-stirred reactor oxidation of alkane-rich FACE gasoline fuels. Proc Combust Inst 2017;36:517-524.

21. AlAbbad M, Javed T, Khaled F, Badra J, Farooq A. Ignition delay time measurements of primary reference fuel blends. Combust Flame 2017;178:205-216.

22. Cai L, Pitsch H. Optimized chemical mechanism for combustion of gasoline surrogate fuels. Combust Flame 2015;162:1623-1637.

23. Callahan C, Held T, Dryer F, Minetti R, Ribaucour M, Sochet L, et al. Experimental data and kinetic modeling of primary reference fuel mixtures. Symp (Int) Combust 1996;26:739-746.

24. Fieweger K, Blumenthal R, Adomeit G. Self-ignition of SI engine model fuels: a shock tube investigation at high pressure. Combust Flame 1997;109:599-619.

25. Tanaka S, Ayala F, Keck JC, Heywood JB. Two-stage ignition in $\mathrm{HCCl}$ combustion and $\mathrm{HCCl}$ control by fuels and additives. Combust Flame 2003;132:219-239.

26. Vanhove G, Petit G, Minetti R. Experimental study of the kinetic interactions in the lowtemperature autoignition of hydrocarbon binary mixtures and a surrogate fuel. Combust Flame 2006;145:521-532.

27. Bradley D, Hicks R, Lawes M, Sheppard C, Woolley R. The measurement of laminar burning velocities and Markstein numbers for iso-octane-air and iso-octane-n-heptane-air mixtures at elevated temperatures and pressures in an explosion bomb. Combust Flame 1998;115:126-144.

28. Huang $Y$, Sung C, Eng J. Laminar flame speeds of primary reference fuels and reformer gas mixtures. Combust Flame 2004;139:239-251.

29. Jerzembeck S, Peters N, Pepiot-Desjardins P, Pitsch H. Laminar burning velocities at high pressure for primary reference fuels and gasoline: Experimental and numerical investigation. Combust Flame 2009;156:292-301.

30. Liao Y-H, Roberts WL. Laminar flame speeds of gasoline surrogates measured with the flat flame method. Energy Fuels 2016;30:1317-1324.

31. Gauthier B, Davidson D, Hanson R. Shock tube determination of ignition delay times in full-blend and surrogate fuel mixtures. Combust Flame 2004;139:300-311.

32. Li H, Yu L, Lu X, Ouyang L, Sun S, Huang Z. Autoignition of ternary blends for gasoline surrogate at wide temperature ranges and at elevated pressure: Shock tube measurements and detailed kinetic modeling. Fuel 2016;181:916-925.

33. Dirrenberger P, Glaude P-A, Bounaceur R, Le Gall H, da Cruz AP, Konnov A, et al. Laminar burning velocity of gasolines with addition of ethanol. Fuel 2014;115:162-169. 
34. Chung J, Lee S, An H, Song S, Chun KM. Rapid-compression machine studies on two-stage ignition characteristics of hydrocarbon autoignition and an investigation of new gasoline surrogates. Energy 2015;93:1505-1514.

35. Fikri M, Herzler J, Starke R, Schulz C, Roth P, Kalghatgi G. Autoignition of gasoline surrogates mixtures at intermediate temperatures and high pressures. Combust Flame 2008;152:276-281.

36. Zhong B-J, Zheng D. A chemical mechanism for ignition and oxidation of multi-component gasoline surrogate fuels. Fuel 2014;128:458-466.

37. Cannella W, Foster F, Gunter G, Leppard W FACE Gasolines and Blends with Ethanol: Detailed Characterization of Physical and Chemical Properties, CRC Report No AVFL-24, 2014.

38. Javed T, Nasir EF, Es-sebbar E-t, Farooq A. A comparative study of the oxidation characteristics of two gasoline fuels and an n-heptane/iso-octane surrogate mixture. Fuel 2015;140:201-208.

39. Javed T, Ahmed A, Lovisotto L, Issayev G, Badra J, Sarathy SM, et al. Ignition studies of two lowoctane gasolines. Combust Flame 2017;185:152-159.

40. Ahmed A, Goteng G, Shankar VSB, Al-Qurashi K, Roberts WL, Sarathy SM. A computational methodology for formulating gasoline surrogate fuels with accurate physical and chemical kinetic properties. Fuel 2015;143:290-300.

41. CloudFlame. Octane Number Calculator, https://cloudflame.kaust.edu.sa/fuel/octane calc/; 2010 [accessed 2 Jul 2018].

42. Ayass WW, Nasir EF, Farooq A, Sarathy SM. Mixing-structure relationship in jet-stirred reactors. Chem Eng Res Des 2016;111:461-464.

43. Zhang K, Banyon C, Bugler J, Curran HJ, Rodriguez A, Herbinet O, et al. An updated experimental and kinetic modeling study of $n$-heptane oxidation. Combust Flame 2016;172:116-135.

44. Dagaut $P$, Cathonnet $M$, Rouan J, Foulatier R, Quilgars A, Boettner J, et al. A jet-stirred reactor for kinetic studies of homogeneous gas-phase reactions at pressures up to ten atmospheres $(\approx 1$ MPa). J Phys E 1986;19:207.

45. Mehl M, Wagnon S, Tsang K, Kukkadapu G, Pitz W, Westbrook C, et al. A comprehensive detailed kinetic mechanism for the simulation of transportation fuels, Lawrence Livermore National Laboratory (LLNL), Livermore, CA, 2017.

46. Metcalfe WK, Burke SM, Ahmed SS, Curran HJ. A hierarchical and comparative kinetic modeling study of C1- C2 hydrocarbon and oxygenated fuels. Int J Chem Kinet. 2013;45:638-675.

47. Bugler J, Marks B, Mathieu O, Archuleta R, Camou A, Grégoire C, et al. An ignition delay time and chemical kinetic modeling study of the pentane isomers. Combust Flame 2016;163:138-156.

48. Sarathy SM, Westbrook CK, Mehl M, Pitz WJ, Togbe C, Dagaut P, et al. Comprehensive chemical kinetic modeling of the oxidation of 2-methylalkanes from C7 to C20. Combust Flame 2011;158:2338-2357.

49. Wang Z, Mohamed SY, Zhang L, Moshammer K, Popolan-Vaida DM, Shankar VSB, et al. New insights into the low-temperature oxidation of 2-methylhexane. Proc Combust Inst 2017;36:373382.

50. Atef N, Kukkadapu G, Mohamed SY, Rashidi MA, Banyon C, Mehl M, et al. A comprehensive isooctane combustion model with improved thermochemistry and chemical kinetics. Combust Flame 2017;178:111-134.

51. Al Rashidi MJ, Mehl M, Pitz WJ, Mohamed S, Sarathy SM. Cyclopentane combustion chemistry. Part I: Mechanism development and computational kinetics. Combust Flame 2017;183:358-371.

52. Kukkadapu G, Kang D, Wagnon SW, Zhang K, Mehl M, Palacios MM, et al. Kinetic modeling study of surrogate components for gasoline, jet and diesel fuels: C7-C11 methylated aromatics. Proc Combust Inst 2018:under review.

53. Kee R, Rupley F, Miller J, CHEMKIN-PRO 15112, Reaction Design, San Diego, CA. 2011.

54. Law CK, Combustion physics. 2nd ed. Cambridge: Cambridge university press; 2010. 
55. Glassman I, Yetter RA, Glumac NG, Combustion. 5th ed. New York: Elsevier; 2014.

56. Wang Z, Sarathy SM. Third $\mathrm{O} 2$ addition reactions promote the low-temperature auto-ignition of n-alkanes. Combust Flame 2016;165:364-372.

57. Battin-Leclerc F. Detailed chemical kinetic models for the low-temperature combustion of hydrocarbons with application to gasoline and diesel fuel surrogates. Prog Energ Combust Sci 2008;34:440-498.

58. Wang Z, Popolan-Vaida DM, Chen B, Moshammer K, Mohamed SY, Wang H, et al. Unraveling the structure and chemical mechanisms of highly oxygenated intermediates in oxidation of organic compounds. Proc Natl Acad Sci 2017;201707564.

59. Dagaut $P$, Pengloan $G$, Ristori A. Oxidation, ignition and combustion of toluene: Experimental and detailed chemical kinetic modeling. Phys Chem Chem Phys 2002;4:1846-1854.

60. Wang Z, Chen B, Moshammer K, Popolan-Vaida DM, Sioud S, Shankar VSB, et al. n-Heptane cool flame chemistry: Unraveling intermediate species measured in a stirred reactor and motored engine. Combust Flame 2018;187:199-216.

61. Curran HJ, Pitz W, Westbrook C, Callahan G, Dryer F. Oxidation of automotive primary reference fuels at elevated pressures. Symp (Int) Combust 1998;27:379-387.

62. Dagaut $\mathrm{P}$, Reuillon $\mathrm{M}$, Cathonnet $\mathrm{M}$. High pressure oxidation of liquid fuels from low to high temperature. 1. n-Heptane and iso-Octane. Combust Sci Technol 1993;95:233-260.

63. Vuilleumier D, Selim H, Dibble R, Sarathy M Exploration of heat release in a homogeneous charge compression ignition engine with primary reference fuels, SAE Technical Paper, 2013.

64. Vuilleumier D, Kozarac D, Mehl M, Saxena S, Pitz WJ, Dibble RW, et al. Intermediate temperature heat release in an $\mathrm{HCCl}$ engine fueled by ethanol/n-heptane mixtures: An experimental and modeling study. Combust Flame 2014;161:680-695.

65. Zhang Y, Somers KP, Mehl M, Pitz WJ, Cracknell RF, Curran HJ. Probing the antagonistic effect of toluene as a component in surrogate fuel models at low temperatures and high pressures. A case study of toluene/dimethyl ether mixtures. Proc Combust Inst 2017;36:413-421. 